\title{
THE TECHNICAL FEASIBILITY OF THE USE OF RUBBER CHIPS IN THE PRODUCTION OF PERMEABLE CONCRETE FOR URBAN PAVING - CASE STUDY
}

\section{Raimundo de Oliveira Monteiro Junior ${ }^{1}$, Murilo Ferreira dos Santos ${ }^{2}$, Matheus Santos Freitas ${ }^{3}$, Darlei dos Anjos Lavor ${ }^{4}$}

\author{
${ }^{1,4}$ Centro Universitário do Norte (UNINORTE). Manaus-AM. \\ ${ }^{2}$ Instituto de Ensino Superior Blauro Cardoso de Mattos (FASERRA). Manaus-AM. \\ ${ }^{3}$ Instituto Brasileiro de Educação Continuada (INBEC). Manaus-AM.
}

Email: junior18_stm@hotmail.com; mullsantos@gmail.com; matheuseng89@gmail.com; darleilavor27@gmail.com

Received: August 19th, 2019

Accepted: August 22 $2^{\text {th }}, 2019$

Published: September $30^{\text {th }}$, 2019

Copyright $(02016$ by authors and Institute of Technology Galileo of Amazon (ITEGAM). This work is licensed under the Creative Commons Attribution International License (CC BY 4.0). https://creativecommons.org/lice nses/by/4.0/

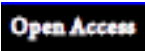

\begin{abstract}
The accumulation of solid wastes that add up to other types of wastes makes the environment more and more limited, with limited space due to its useful life. Given this fact, this research gives rise to the technical feasibility of using tire tube rubber associated with permeable concrete for use in urban paving. The goal is to develop a dosage from which this new material will come to commercial use both in the form of blocks, pavers, among other materials. The reference trait was used through the characterization of the materials and the dosage of 1:4 (cement:gravel 0) was determined, with a water/cement factor $(\mathrm{a} / \mathrm{c})$ of 0,32 . The replacement of gravel by rubber chips was $50 \%$ making the dosage like this: 1:2:2:0.32. The average mechanical strength of the reference line was $27,2 \mathrm{MPa}$ and the dosage with rubber chips was 25,5 MPa. Although the resistance has been limited to what was determined in the dosage (25 MPa), the feasibility of using this material meets the requirements of NBR 9781, and can be used in environments with light demand, such as sidewalks, squares and bike paths. Therefore, the previous analyzes of the water filtered by the specimen were positive regarding the $\mathrm{pH}$, acidity and alkalinity characteristics and returned to the environment without contamination.
\end{abstract}

Keywords: Eraser. Permeable Concrete. Environment.

\section{A VIABILIDADE TÉCNICA DO USO DE LASCAS DE BORRACHA NA PRODUÇÃO DE CONCRETO PERMEÁVEL PARA PAVIMENTAÇÃO URBANA - ESTUDO DE CASO}

\section{RESUMO}

O acúmulo de resíduos sólidos que se agregam aos outros tipos de resíduos tornam o meio ambiente cada vez mais, com um espaço limitado devido o seu tempo de vida útil. Diante desse fato, esta pesquisa enseja a viabilidade técnica do uso da borracha das câmaras de ar para pneus associado ao concreto permeável para o uso em pavimentação urbana. O objetivo é desenvolver uma dosagem do qual esse novo material venha ao uso comercial tanto em forma de blocos, pavers, dentre outros materiais. Foi empregado o traço de referência através das caracterizações dos materiais e determinado a dosagem de 1:4 (cimento:brita 0), com o fator água/cimento $(\mathrm{a} / \mathrm{c})$ de 0,32 . A substituição da brita pelas lascas de borracha foram de 50\% tornando a dosagem assim: 1:2:2:0,32. A média da resistência mecânica do traço de referência foi de 27,2 MPa e da dosagem com lascas de borracha foi de 25,5 $\mathrm{MPa}$. Apesar da resistência ter ficado no limite do que foi determinado na dosagem (25 MPa), a viabilidade do uso desse material atende aos requisitos da norma NBR 9781, podendo ser utilizado em ambientes com demanda leve, tais como: calçadas, praças e ciclovias. Logo, as análises prévias da água filtrada pelo corpo de prova foram positivas em relação as características do $\mathrm{pH}$, da acidez e da alcalinidade e, volta para o meio ambiente sem contaminação.

Palavras-Chaves: Borracha. Concreto Permeável. Meio Ambiente. 


\section{INTRODUÇÃO}

Compartilhar conhecimento sempre foi, e ainda é, um hábito essencial para o desenvolvimento da humanidade. Essa qualidade foi importante para o progresso das civilizações, tornando o mundo o que ele é hoje. No entanto, antes de compartilhar conhecimento, é necessário produzi-lo. A produção científica é o método responsável pela criação de novos conhecimentos, que agregam valor científico tanto à comunidade acadêmica quanto à sociedade em geral [1].

[2] O crescimento populacional vertiginoso é realidade eminente no século em que vivemos e que paralelamente podemos verificar um cenário novo de transição entre áreas urbanas mais densificadas representando em um acréscimo de $84 \%$ em relação às áreas rurais que decresceram $16 \%$. E essas mudanças trazem consigo a insuficiência dos sistemas de drenagem que não são capazes de comportarem adequadamente maiores volumes de contribuição.

Com a contínua evolução dos meios de transportes usados pelo homem e sua constante necessidade de locomoção, a área de transportes e pavimentação acaba recebendo cada vez mais atenção. O modal rodoviário é responsável por cerca de $60 \%$ do transporte nacional, com isso os métodos de construção dos pavimentos têm evoluído de maneira acentuada nas últimas décadas. Na medida em que a rede rodoviária pavimentada passou a representar um altíssimo patrimônio, os métodos de fabricação, seus projetos e suas qualidades de execução, assim como sua conservação tiveram de ser aperfeiçoados [1].

O pavimento é uma estrutura de várias camadas assentadas sobre a terraplanagem. É destinada técnica e economicamente a resistir aos esforços do tráfego e aos desgastes tornando mais durável a superfície, melhorando as condições de rolamento, proporcionando conforto e segurança [3].

[4] A utilização de resíduos descartados está sendo cada vez mais explorada pela construção civil, tendo como o objetivo a incorporação de novas propriedades ao concreto, conservando os materiais finitos usados como o agregado miúdo e graúdo, e diminuindo os impactos ambientais em nossa sociedade.

Quando se elabora um artefato, tem-se os resíduos sólidos gerados no instante de sua confecção e aqueles que são relacionados ao pós-consumo desse material. Nesse contexto, a maior fonte produtora de resíduos sólidos pós-consumo, são os pneus inservíveis, que contêm em sua composição principalmente o copolímero de butadieno e estireno (SBR) e a borracha natural (NR) [5].

A utilização de resíduos em concreto tem se mostrado uma boa alternativa na redução do impacto causado pelo consumo desordenado de matéria-prima e pela redução das áreas de disposição em virtude do grande volume de resíduos descartados a cada ano no mundo [6].

Dentre estes resíduos, a borracha de pneus vem sendo amplamente utilizada na produção de concretos e artefatos cimentícios, de forma que os estudos científicos da incorporação desses resíduos vêm crescendo significativamente [7].

A utilização de pavimentos intertravados com blocos prémoldados de concreto vem crescendo em todo o mundo, particularmente no Brasil. Ele estudou pavers de concreto com diferentes níveis de incorporação de borracha, 8\%, 10\%, 12\%, 15\% e $20 \%$ em volume, e concluiu que há queda de resistência à compressão [8].

Diante desses fatos, este artigo desenvolveu uma pesquisa, com a finalidade de verificar a viabilidade, tanto física quanto mecânica, da utilização dos resíduos de câmara de ar para pneus em concreto permeável para pavimento com tráfego leve, do tipo: calçadas, estacionamentos e etc., usando parcialmente esses resíduos e/ ou deixando de usar inteiramente o agregado com apenas pasta de cimento entre as porcentagens de 50 a $100 \%$.

\section{REVISÃO BIBLIOGRÁFICA}

\section{II.1 A HISTÓRIA DA BORRACHA PELO MUNDO}

Com a evolução da humanidade tendo que se adaptar com invenções no seu dia a dia para facilitar suas rotinas, desde a era medieval até agora com a internet; a evolução trouxe inúmeras melhorias para o nosso cotidiano.

Em 1834, o presidente dos Estados Unidos, Andrew Jackson, foi presenteado por uma alfaiataria, com um terno impermeabilizado com uma goma grudenta, a borracha. $\mathrm{O}$ terno foi utilizado foi utilizado numa cerimônia em um dia chuvoso, mantendo-se seco, porem alguns dias depois o terno foi inutilizado, pois a goma grudenta derreteu [9]. [10] A goma aplicada ao terno ficou conhecida como borracha. Isso aconteceu em 1839. Goodyear encontrou a fórmula: endurecer no frio e derreter no calor. Em 1845, um engenheiro escocês revestiu as rodas de sua carruagem com borracha vulcanizada inflada com ar, para diminuir o barulho e torná-la mais macia. [11] As rodas anteriormente de madeira e ferro, ao serem revestidas com a borracha vulcanizada, ganhava forma. A borracha aumentou a segurança nas freadas e diminuiu as trepidações nos carros. [10] Em 1888, John Boyd Dunlop, também escocês, mas que vivia na Irlanda, descobriu uma maneira de evitar as quedas de seus filhos na bicicleta: costurou uma válvula a um tubo de borracha e encheu esse tubo com ar, cobrindo com um pedaço de lona. Assim surgiu o primeiro pneu para bicicletas. Na França, os irmãos Édouard e André Michelin foram os primeiros a patentear o pneu para automóveis. Numa corrida entre Paris e Bordeaux, em 1895, os irmãos Michelin inscreveram um carro com pneu inflável, que ganhou a corrida com certa folga. O problema eram os constantes furos nos pneus.

[10] Em 1903, diante do grande sucesso, eles foram negociar seu produto numa pequena, mas promissora cidade americana chamada Detroit, onde acabava de ser montada uma grande fábrica de automóveis: a Ford. No Brasil, a história começa com escritórios de importação de firmas europeias e norteamericanas.

Em 1939, seria inaugurada a primeira fábrica de pneus do país: a Goodyear. No ano seguinte viria a Firestone, e em 1941 a Pirelli, que já tinha aqui uma fábrica de fios elétricos.

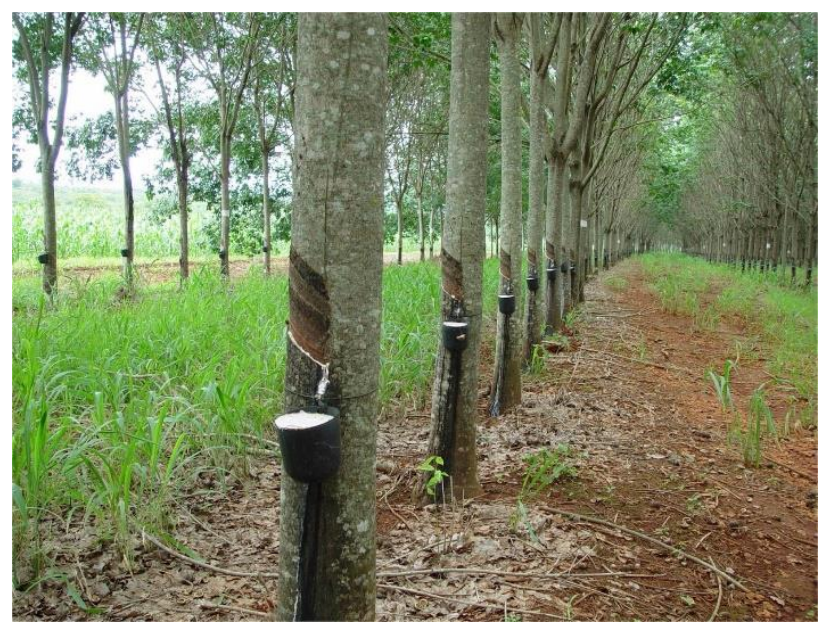

Figura 1 - Plantio de seringueira e coleta da matéria prima para a borracha, o leite da seringueira.

Fonte: [12] Líder agronomia, (2012). 


\section{II.2 A CÂMARA DE AR PARA PNEUS}

A borracha natural fez-se presente na história do Brasil, entre a segunda metade do século XIX e início do século XX, trazendo riquezas e prosperidade para a região norte, sustentando assim um dos mais importantes ciclos de desenvolvimento do país [13].

Com o passar do tempo a borracha foi sendo cada vez mais estudada, até que criou-se na Alemanha a tecnologia para fabricála artificialmente a partir do petróleo, sendo criado os elastômeros [14].

O negro de fumo é derivado da combustão incompleta do petróleo, ele é um carbono amorfo, também derivado do carvão. Sua produção é feita em fornos especiais de forma controlada onde se obtém vários tipos de negro de fumo aplicados na indústria da borracha. Ele possui propriedades que conferem a borracha poder de pigmentação e resistência mecânica. No pneu são adicionados 8 tipos de negro de fumo, o que aumenta muito sua vida útil em aproximadamente 16 vezes [15]. Hoje já temos pneus capazes de rodar por vários quilômetros sem que esteja inflado, isso não danificando sua carcaça e sem comprometer a estabilidade do veículo [16].

O sucesso dos pneus com câmara (tire tube) começou em 1895, na época corridas de veículos automotores eram frequentes. Os irmãos Michelin inscreveram na corrida, um carro com pneus infláveis, uma novidade, já que todos os carros usavam pneus de borracha maciça. O carro acabou ganhando a corrida com o êxito e assim, os pneus infláveis passaram a ser itens indispensáveis nas grandes fábricas de automóveis [17]. Em meados de 1900 aconteceram vários fatos que ocasionaram fortes mudanças na evolução dos pneus. O primeiro pneu sem câmara (tubeless) foi patenteado pela Goodyear Tire and Rubber Company, no ano de 1903, mas ele só foi comercializado em 1954 [18].

[19] A diferença entre os pneus com e sem câmara de ar reside no fato dos primeiros apresentarem uma câmara de ar independente, de borracha, enquanto nos últimos o ar é armazenado no próprio pneus.

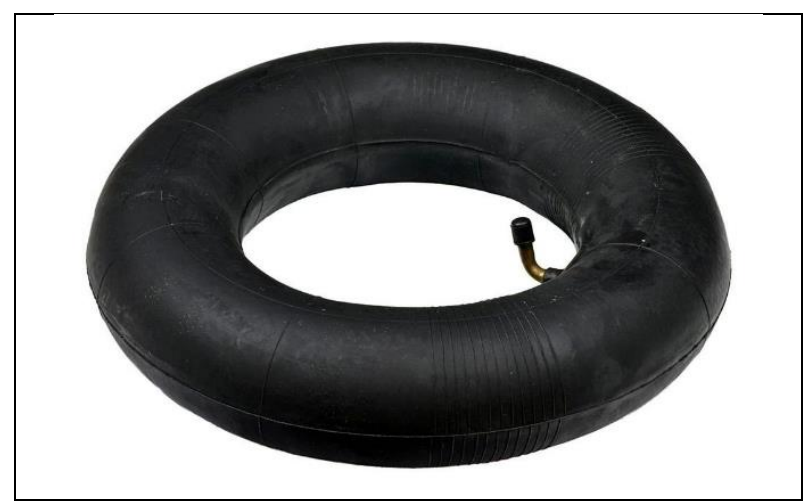

Figura 2 - Câmara de ar para pneu de 200x50 cadeira rodas motorizadas.

Fonte: [20] Tudo de ferramentas, (2019).

\section{MATERIAIS E MÉTODOS}

\section{III.1 MATERIAIS UTILIZADOS NA PREPARAÇÃO DO CONCRETO PERMEÁVEL}

Os elementos empregados como suporte para a confecção dos concretos permeáveis desta pesquisa foram o cimento Portland, a brita $\mathrm{n}^{\circ} .0$ e a água.

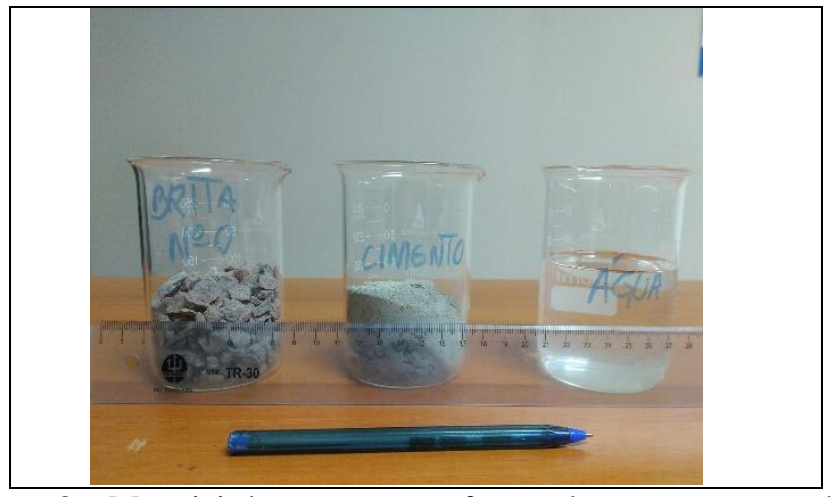

Figura 3 - Materiais base para a confecção do concreto permeável dentro de um copo de bequer.

Fonte: Autores (2019).

\section{III.1.1 AGLOMERANTE - CIMENTO PORTLAND}

Nesta pesquisa, o tipo do cimento usado foi CP IV-32 (Resistente) da marca CEMEX, produzido e comercializado no polo industrial de Manaus. Essa é a marca mais utilizada nas regiões da capital amazonense.

As análises de caracterizações para verificar se a qualidade do cimento está adequada para o uso foram as seguintes:

a) Análise da finura por meio da peneira $75 \mu \mathrm{m}\left(\mathrm{n}^{\circ}\right.$. 200) [21];

b) Análise da massa específica [22];

c) Análise da pasta de consistência normal [23];

d) Análise dos tempos de pega [24]

e) Análise da resistência à compressão [25];

Todos os métodos de ensaios para a análise de caracterização do cimento relacionados acima foram realizados no laboratório de Materiais de Construção e Técnicas Construtivas do Centro Universitário do Norte (UNINORTE) com o acompanhamento técnico. A figura 4, a seguir, demonstra o material utilizado.

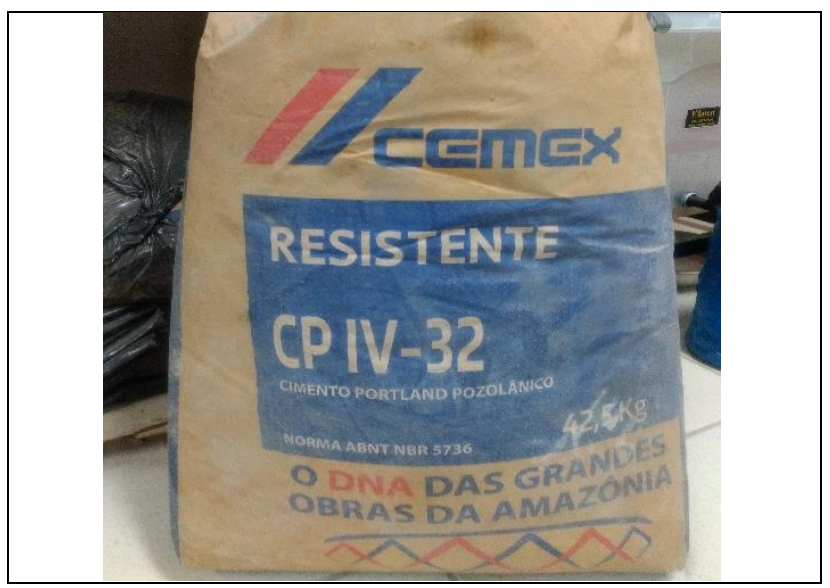

Figura 4 - Cimento Portland da marca Cemex utilizado para esta pesquisa.

Fonte: Autores, (2019).

\section{III.1.2 AGREGADOS - BRITA 0}

O agregado (brita 0) foi comprado em uma loja de materiais de construção localizada no centro de Manaus. A caracterização da brita 0 foi realizada, também, no laboratório de Materiais de Construção do UNINORTE. Todos os métodos de ensaios descritos abaixo, atendem as especificações da Associação Brasileira de Normas Técnicas (ABNT). A seguir, tem-se a relação das normas utilizadas para a determinação da caracterização da 
brita 0 , assim como a figura 5 mostra o material em um recipiente de porcelana.

a) Material fino que passa através da peneira $75 \mu \mathrm{m}$, por lavagem [26];

b) Composição granulométrica [27];

c) Massa unitária e volume de vazios [28];

d) Massa específica, massa específica aparente e absorção de água [29].

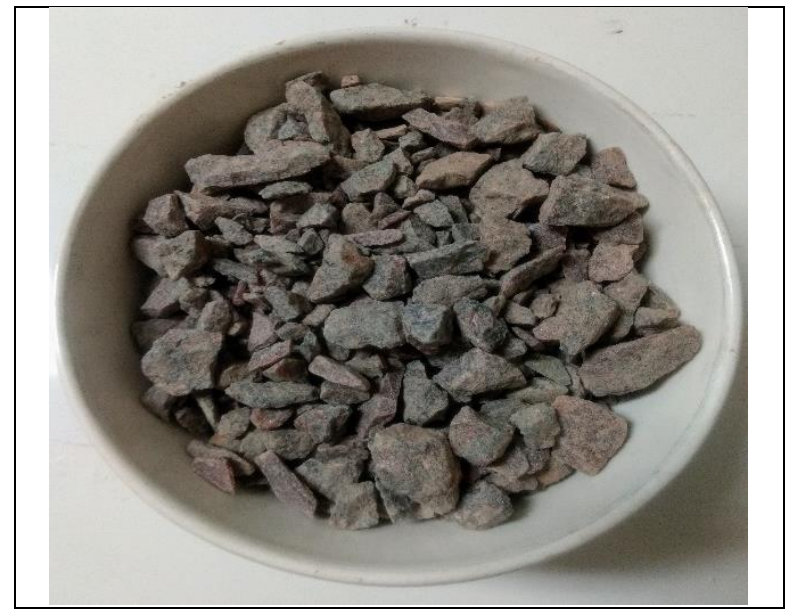

Figura 5 - Agregado (brita 0) disposto em um recipiente de porcelana usado para a confecção dos concretos.

Fonte: Autores, (2019).

\section{III.1.3 ÁGUA}

Para a confecção dos concretos, a água utilizada foi através do fornecimento público da cidade de Manaus, ÁGUAS DE MANAUS S/A, onde foi adquirida no laboratório da Instituição já mencionada anteriormente no escopo desta pesquisa.

\section{III.1.4 LASCAS DE CÂMARAS DE AR PARA PNEUS UTILIZADAS NO CONCRETO PERMEÁVEL}

As câmaras de ar para pneus utilizadas nesta pesquisa foram compradas em uma borracharia localizada no bairro Praça 14 de janeiro, zona centro sul de Manaus; já que a doação desse material dita por muitos proprietários de diversas borracharias, era inviável devido a sua influente utilização.

Após a compra, o material foi cortado com o auxílio de uma tesoura com as medidas de $20 \mathrm{~mm}$ para cada lado de um quadrado/ retângulo. A figura 6, a seguir, expõe o material cortado em cima de uma mesa branca para dar destaque à borracha com um escalímetro na lateral na escala de 1:100 dando ênfase ao tamanho do material pronto para o uso. Nota-se, ainda na figura 6 , que a borracha apresenta oxidação de ferro em sua base apresentando um destaque pelo seu tempo de vida útil.

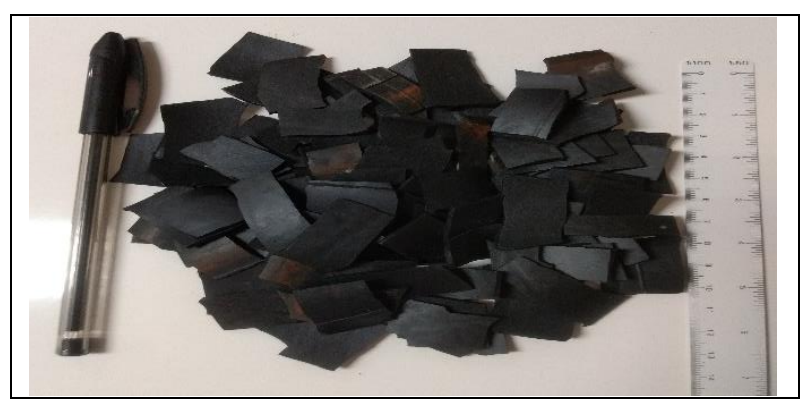

Figura 6 - Material usado no concreto permeável (borrracha da câmara de ar para pneu), cortada em $20 \mathrm{~mm}$ pronta para o uso.

Fonte: Autores, (2019).

\section{2 CONFECÇÃO DOS CONCRETOS E MOLDAGEM DOS CORPOS DE PROVA}

[30] O traço referência abrange uma grande relação dos materiais e conhecimentos da fundamentação, ele engloba o concreto permeável sem utilização de agregado miúdo. Sendo assim, apenas cimento, brita e água .

Para o cálculo, foram empregadas as propriedades das caracterizações dos materiais encontradas em cada análise realizada, tais como: granulometria (brita) massa específica (cimento e brita), dentre outro citados nos itens III.1.1 e III.1.2 no escopo desta pesquisa. $O$ traço referência final ficou como 1:4 (cimento:brita).

A relação água cimento foi mantida em todos os traços, [31], em que foi estudada a melhor relação água/cimento para o concreto permeável. Notou-se que há uma curva ótima para a relação, sendo que o intervalo da pesquisa foi de 0,30 até 0,38 , e constou-se a partir de 0,34 a resistência é comprometida, os melhores resultados foram obtidos com 0,32 , e não aconselhou-se uma relação menor do que 0,30 [30].

A mistura dos materiais foi realizada em uma betoneira estacionaria. Primeiramente colocado a brita e em seguida o cimento e acionado o botão para a mistura. Feito isso, a água foi adicionada cautelosamente e realizado o processo de homogeneização do concreto. A figura 7, a seguir, mostra a adição da água com o auxílilio de uma proveta plástica na betoneira em movimento.

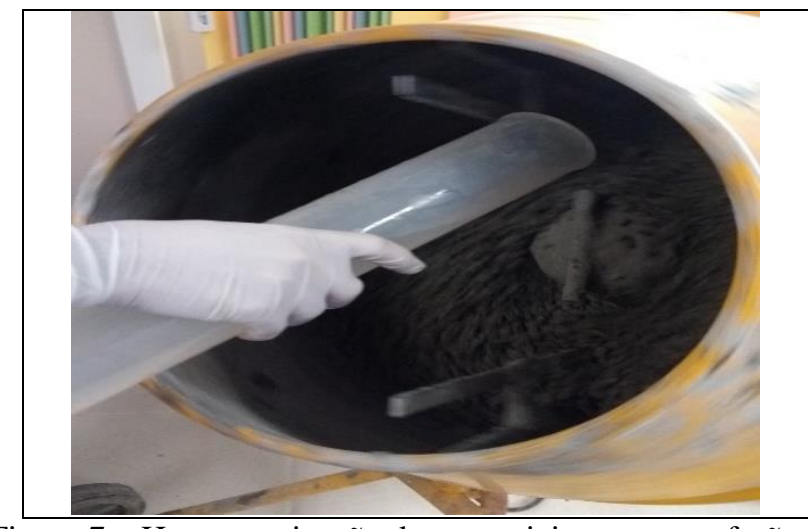

Figura 7 - Homogeneização dos materiais para a confeção do concreto permeável convencional.

Fonte: Autores, (2019).

Após a homogeneização dos materiais na betoneira, os procedimentos de moldagem dos corpos de prova atendem as especificações normativas da Associação Braseileira de Normas Técnicas (ABNT), detalhando o passo a passo de como deve ser realizada a moldagem para o melhor desempenho do concreto [32]. A figura 8, abaixo, apresenta os corpos de prova já moldados.

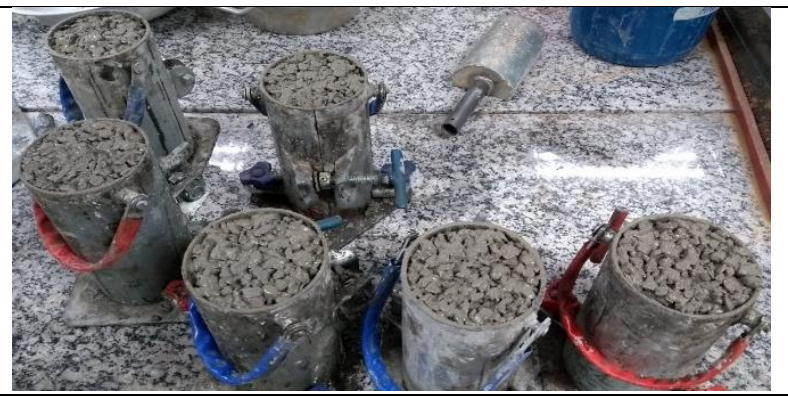

Figura 8 - Moldagem realizada dos corpos de prova do concreto permeável do traço referência.

Fonte: Autores, (2019). 
Todos os procedimentos descritos neste item atendem aos dois tipos de concreto desenvolvidos nesta pesquisa, o concreto permeável convencional e o concreto permeável com adição das lascas de borracha.

As dimensões das formas usadas para a moldagem são de $100 \mathrm{~mm}$ por $200 \mathrm{~mm}$.

\section{III.3 CURA DOS CORPOS DE PROVA}

A cura dos corpos de prova foram divididas em 3 etapas:

$1^{\text {a }}$ etapa - após a moldagem os concretos foram cobertos com o plástico acrilico por $24 \mathrm{~h}$ para que impedisse a evaporação da água;

$2^{a}$ etapa - em seguida, os concretos foram mantidos dentro das formas por 7 dias em temperatura ambiente;

$3^{\text {a }}$ etapa - Depois do prazo de 7 dias, os concretos foram retirados das formas e matidos um do lado do outro por mais 20 dias apenas com a temperatura um do outro. A figura 9, mostra um corpo de prova do concreto permeável com as lascas de borracha após a desforma e, a figura 10, demonstra o processo de cura por mais 20 dias, também após a desforma.

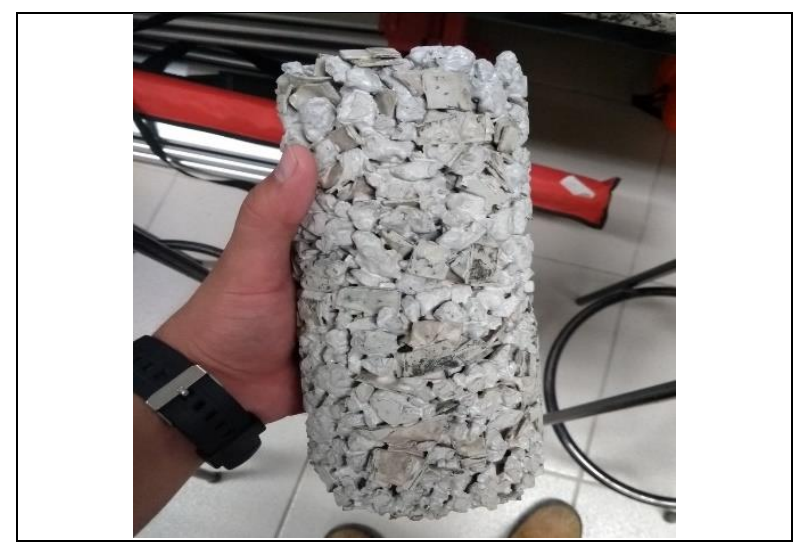

Figura 9-Desforma do concreto permeável com as lascas de borracha após o prazo de 7 dias.

Fonte: Autores, (2019).

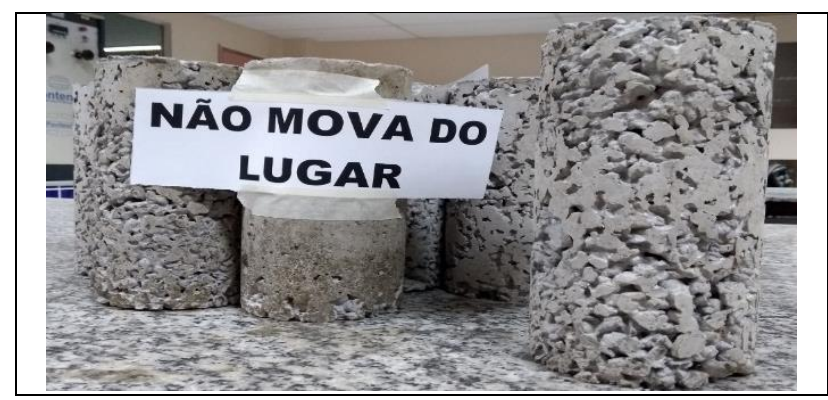

Figura 10 - Cura por mais 20 dias do concreto permeável convencional após a desforma acondicionados apenas com a temperatura um do outro. Fonte: Autores, (2019).

\section{III.4 ANÁLISE DA ÁGUA FILTRADA PELOS CORPOS DE PROVA}

O método para a análise da água filtrada pelos corpos de prova do concreto permeável foi um método simples e que é muito comum usar em piscinas e aquário para medir o $\mathrm{pH}$, a acidez, a alcalinidade e dentre outros. Esse procedimento utilizado é comprado em qualquer loja de equipamentos e materiais para piscinas. O objetivo desta análise prévia da água é identificar a qualidade dessa água que retorna para o meio ambiente.
A figura 11, a seguir, apresenta todos os materiais e equipamentos utilizados tanto para a filtragem da água como os procedimentos usados para a análise de qualidade.

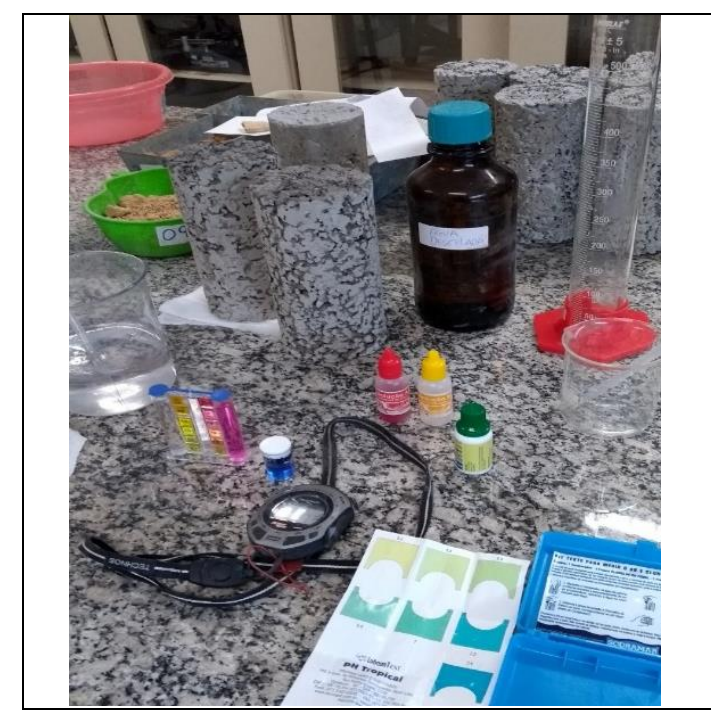

Figura 11 - Materiais e equipamentos disposto na bancada para a análise da qualidade da água filtrada pelos corpos de prova de concreto permeável.

Fonte: Autores, (2019).

\section{III.5 RUPTURA DOS CORPOS DE PROVA}

Este método de ensaio atende as especificações da norma da ABNT [33].

Após o período de cura, os corpos de prova foram levados para uma prensa de compressão axial, disponibilizada pelo laboratótio de Materiais de Construção do UNINORTE para verificar a resistência mecânica de cada um deles.

Abaixo, a figura 12 demosntra o processo de ruptura, através da prensa, onde os corpos de prova foram submetidos para a análise da resistência mecânica.

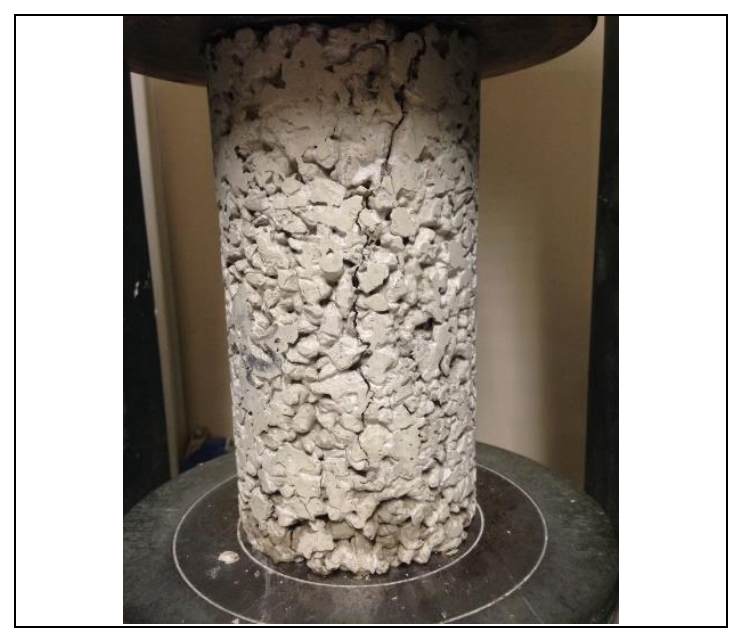

Figura 11 - Análise de compressão axial do corpo de prova do concreto permeável.

Fonte: Autores, (2019).

\section{RESULTADOS E DISCUSSÕES IV.1 DOSAGEM DO TRAÇO UNITÁRIO DOS CONCRETOS.}

Conforme os dados coletados pelas caracterizações dos materiais, a dosagem dos traços de concreto permeável, ficaram: 
Tabela 1 - Dosagem unitária dos concretos - convencional e com lascas de borracha.

\begin{tabular}{|c|c|c|c|}
\hline $\begin{array}{c}\text { Dosagem } \\
\text { convencional }\end{array}$ & $\begin{array}{c}\text { FCK } \\
(\mathbf{M P a})\end{array}$ & $\begin{array}{c}\text { FC28 } \\
(\mathbf{M P a})\end{array}$ & $\begin{array}{c}\text { Fator 31MPa } \\
(\mathbf{a} / \mathbf{c})\end{array}$ \\
\hline $1: 4: 0,32$ & 25,0 & 31,6 & 0,32 \\
\hline $\begin{array}{c}\text { Dosagem com } \\
\text { as lascas de } \\
\text { borracha }\end{array}$ & $\begin{array}{c}\text { FCK } \\
(\mathbf{M P a})\end{array}$ & $\begin{array}{c}\text { FC28 } \\
(\mathbf{M P a})\end{array}$ & $\begin{array}{c}\text { Fator 31MPa } \\
(\mathbf{a} / \mathbf{c})\end{array}$ \\
\hline $1: 2: 2: 0,32$ & 25,0 & 31,6 & 0,32 \\
\hline \multicolumn{4}{|c|}{ Fonte: Autores, (2019). } \\
\hline
\end{tabular}

\section{IV.2 ANÁLISE DA ÁGUA FILTRADA PELOS CORPOS DE PROVA}

As análises das águas filtradas pelos corpos de prova obtiveram os seguintes resultados, conforme a tabela 2 , a seguir.

Tabela 2 - Dosagem unitária dos concretos - convencional e com lascas de borracha.

\begin{tabular}{|c|c|c|c|c|}
\hline \multirow[b]{2}{*}{$\begin{array}{c}\text { Características da Água } \\
\text { Filtrada pelo Corpos de } \\
\text { Prova de concreto }\end{array}$} & \multicolumn{4}{|c|}{ Amostragem } \\
\hline & \multicolumn{2}{|c|}{$\begin{array}{c}\text { Concreto } \\
\text { Convencional }\end{array}$} & \multicolumn{2}{|c|}{$\begin{array}{c}\text { Concreto } \\
\text { com Lascas } \\
\text { de Borracha }\end{array}$} \\
\hline Temperatura $\left({ }^{\circ} \mathrm{C}\right)$ & 26,0 & 25,5 & 24,5 & 24,0 \\
\hline $\begin{array}{l}\text { Potencial Hidrogeniônico } \\
(p H)\end{array}$ & 4,8 & 4,4 & 7,8 & 7,6 \\
\hline Alcalinidade (mg/ ppm) & 140 & 150 & 120 & 120 \\
\hline Acidez & \multicolumn{2}{|c|}{ Presente } & \multicolumn{2}{|c|}{ Ausente } \\
\hline
\end{tabular}

Fonte: Autores, (2019).

Nota-se que nas análises do pH, da alcalinidade e da acidez, a água filtrada pelo concreto com lascas da câmaras de ar para pneus obtiveram uma aceitação melhor do que a água filtrada do concreto convencional, ou seja, a qualidade da água com esse tipo de material volta para o meio ambiente em boas condições.

\section{IV.3 RUPTURA DOS CORPOS DE PROVA}

A seguir, na tabela 3 , demonstra os resultados obtido de acordo com a ruptura de cada corpo de prova em relação as dosagem dos traços de concreto confeccionados.

Tabela 3 - Determinação da resistência à compressão (Mpa) dos corpos de prova dos concretos.

\begin{tabular}{|c|c|c|}
\hline \multicolumn{3}{|c|}{ Resistência à compressão (Mpa) } \\
\hline \multirow[b]{2}{*}{ Idade (dias) } & \multicolumn{2}{|c|}{ Dosagem } \\
\hline & Referência & $\begin{array}{l}\text { Lascas de } \\
\text { Borracha }\end{array}$ \\
\hline \multirow{4}{*}{28} & 27,7 & 26,4 \\
\hline & 27,5 & 25,8 \\
\hline & 27,0 & 25,2 \\
\hline & 26,8 & 24,8 \\
\hline Média & 27,25 & 25,55 \\
\hline
\end{tabular}

Fonte: Autores, (2019).

O gráfico, figura 12 a seguir, mostra a representação do densempenho dos corpos de prova em relação a resistência mecânica das dosagens determinadas para cada concreto desenvolvido. Observa-se que, apesar dos resultados encontrados em MPa dos corpos de prova, a dosagem do concreto permeável com lascas de borracha foi inferior comparado com os resultados encontrados da dosagem de referência. Mas isso não significa que o concreto permeável com lascas de borracha esta fora do determinado pelo traço, muito pelo contrário, atende a dosagem do Fck de 25Mpa.

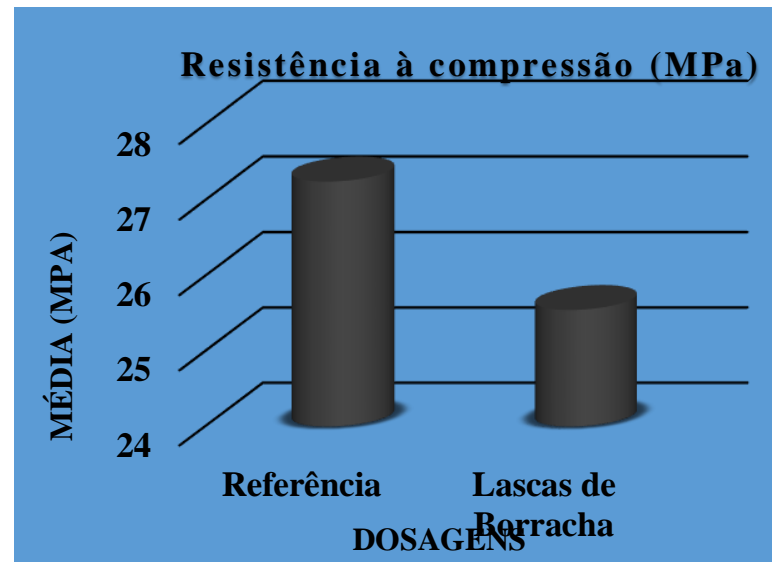

Figura 12 - Representação dos resultados em MPa encontrados na ruptura dos corpos de prova.

Fonte: Autores, (2019).

\section{CONCLUSÃO}

Através das análises de caracterização, identificou-se as propriedades físicas de cada componente desse material desenvolvido, o concreto permeável com lascas de câmaras de ar para pneus. De acordo com o objetivo proposto para esta pesquisa, foi possível identificar a viabilidade técnica do concreto permeável confeccionado com $50 \%$ de brita 0 e $50 \%$ das lascas de borracha.

Todas as análises aqui propostas e desenvolvidas para o conhecimento do comportamento do concreto permeável, atendem as especificações normativas da ABNT. Logo, a viabilidade técnica desse novo material, tende a ajudar no contole da poluição em relação aos resíduos sólidos colaborando com as melhores condições do meio ambiente 'de forma geral, uma vez que as análises da água filtrada pelo concreto permeável produzido com lascas de pneu, volta para o meio ambiente sem alterações de contaminação.

Porém, as dosagens utilizadas para esta pesquisa atigiram o proposto de $25 \mathrm{MPa}$, apesar do valor mínimo de $35 \mathrm{MPa}$ determinado na norma ABNT NBR 9781 para solicitações leves. Todos os resultados encontrados indicam que o uso desse resíduo para esse tipo de concreto para pode ser utilizado em ambientes com demanda leve, tais como: calçadas, praças, ciclovias e ruas de condomínios residenciais.

Ainda que a resistência mecânica desse material ser menor que o valor mínimo de $35 \mathrm{MPa}$ determinado pela norma NBR 9781, é aceitável a sua utilização em pavimentação de baixa intensidade de sobrecarga.

Então, afirma-se que o uso das lascas de borracha torna-se viável na utilização do concreto permeável em vários segmentos, uma vez que seu emprego seja para a pavimentação urbana com tráfego leve. Ainda assim, é necessário aprimorar mais o conhecimento sobre as propriedades e o comportamento desse resíduo integrado na produção de novos concretos.

\section{REFERÊNCIAS BIBLIOGRÁFICAS}

[1] Rolim, L. J.; Moura, V. B. Análise cienciométrica sobre pavimentos de concreto. TCC, curso de Engenharia civil. UniEvangelica. Anápolis, GO. 58p. 2018. 
[2] Virgilis, Afonso Luis Correa de. Procedimentos de projetos e execução de pavimentos permeáveis visando retenção e amortecimento de picos de cheia. Engenharia Ambiental - Espírito Santo do Pinhal, v. 13, n. 2, p. 57-67, jul./dez. 2016. GAUDARD, J. G. P.S.; BARRETO, A. G. Permeabilidade do solo à luz de um desenvolvimento urbano mais sustentável. Disponivel em: <http://www.google.com.br/url?sa=t\&rct=j\&q=\&esrc=s\&sour ce=web\&cd=1\&ved=0CCAQFjAA\&url=http $\% 3 \mathrm{~A} \% 2 \mathrm{~F} \% 2 \mathrm{Fwww}$. teses.usp.br\%2 Fteses\%2Fdisponiveis\%2F3\%2F31 38\%2Ftde08092010-

122549\%2Fpublico\%2FDissertacao_Afonso_Luis_Correa_de_Vi rgiliis.df\&ei=PGqjU5PmN6zIsATExYG gDw\&usg=AFQjCNF79rpPP57RO5Hm_In3AsihRrai4w\&sig2=o _BbY 2WDEFljePtUmpI5TA>. Acesso em maio de 2019.

[3] Bernucci, L.B., Motta, L. M. G., Ceratti, J. A. P., Soares, J. B. Pavimentação Asfáltica: formação básica para engenheiros. Rio de Janeiro: PETROBRAS: ABEDA, 2007.

[4] Canhada, J. C. S.; Altran, D. A.; Ishiki, H. M.; Fidelis, G. N. S.; Dos Santos, R. J. Caracterização física e morfológica de compósitos de concreto com resíduos de borracha vulcanizada Colloquium Exactarum, v. 9, n.3, Jul-Set. 2017, p.65-75. DOI: 10.5747/ce.2017.v09.n3.e $205 . \quad$ Disponível em: <http://revistas.unoeste.br/index.php/ce/article/view/2207/211 4). Acesso em março de 2019.

[5] Adhikari, B.; De, D. \& Maiti, S. - Prog. Polym. Sci., 25, p. 909, (2000).

GUJEL, A. A. et al. Incorporação de Pó de Pneu em uma Formulação para Banda de Rodagem de Pneu de Motocicleta. Polímeros: Ciência e Tecnologia, v. 18, n. 4, p. 320- 325, 2008.

[6] Fioriti, Cesar Fabiano; INO, Akemi; Akasaki, Jorge Luis. Avaliação de blocos de concreto para pavimentação intertravada com adição de resíduos de borracha provenientes da recauchutagem de pneus. Revista online da ANTAC: AC Ambiente Construído, v. 7, n.4, 2007.

[7] Fronza R. Estudo de piso intertravado de concreto com resíduo de borracha de pneus inservíveis visando a redução de consumo de cimento. Dissertação. Programa de PósGraduação da Faculdade de Tecnologia da Universidade Estadual de Campinas. Limeira - SP, 2016.

[8] Fioriti, Cesar Fabiano. Pavimentos intertravados de concreto utilizando resíduos de pneu como material alternativo.2007. Tese (Título de Doutor em Ciências da Engenharia Ambiental). Escola de Engenharia de São Carlos da Universidade de São Paulo. São Carlos, 2007.

[9] Conceição, A. J. M. A indústria de recauchutagem de pneus e suas implicações no transporte no Brasil. São Paulo: FEA/PUC, 1990.

[10] Portal São Francisco. Disponível em: $<$ https://www.portalsaofrancisco.com.br/historia-dobrasil/historia-do-pneu >. Acesso em março 2019.

[11] ANIP. Associação Nacional da indústria de pneumáticos. Disponível em: $\langle$ http://www.anip.com.br $>$. Acesso em março de 2019.
[12] Portal Lider Agronomia - O maior portal de agronomia na internet.

Disponível em: <http://www.lideragronomia.com.br/2012/04/seringueira.html $>$. Acesso em abril de 2019.

[13] Mucambo. Um pouco da história da borracha. Disponível em: $<$ http://www.mucambo.com.br/novosite/institucional/historiad aborracha.pdf $>$. Acesso em abril de 2019.

[14] Recicloteca. Centro de Informação sobre reciclagem e meio ambiente. Borracha e o pneu. Disponível em:〈http://www.recicloteca.org.br/Defaul.asp >. Acesso abril de 2019.

[15] Chemisol. Negro de Fumo. Disponível em:<www.chemisol.com.br/produtos/negro-de-fumo. Global Material Supply Management (GMSM). Negro de Fumo da Borracha. Acesso em abril de 2019.

[16] Silva, A. E. M.; De Castro, V. A. Tecnologia do pneu, fabricação, dimensionamento e aplicação. Disponível em: $<$ http://www.unirv.edu.br/conteudos/fckfiles/files/Arthur\%20 \%C3\%89dico.pdf. $>$. Acesso em abril de 2019.

[17] INFOPNEUS. História do Pneu. Disponível em:http://www.infopneus.com.br/historia-do-pneu/. Acesso em abril de 2019.

[18] Continental. Reinfengrundlagen Pkw. [S.I.]: GmbH, 2009. 30 .

[19] Costa, P. G. Pneus. Disponível em: $<$ http://www.oficinaecia.com.br/bibliadocarro $>$. Acesso em abril de 2019.

[20] Portal Tudo De Ferramentas. Disponível em: $<$ https://www.tudodeferramentas.com.br/camara-de-ar-pneu200-x-50-cadeira-rodas-motorizada>. Acesso em abril de 2019.

[21] Associação Brasileira De Normas Técnicas. NBR 11579 MB3432 Cimento Portland - Determinação da finura por meio da peneira $75 \mu \mathrm{m}$ (nº 200). Rio de Janeiro, 1991.

[22] Associação Brasileira De Normas Técnicas. NBR NM 23 Cimento portland e outros materiais em pó - Determinação da massa específica. Rio de Janeiro, 2001.

[23] Associação Brasileira De Normas Técnicas. NBR NM 43 Cimento portland - Determinação da pasta de consistência normal. Rio de Janeiro, 2003.

[24] Associação Brasileira De Normas Técnicas. NBR NM 65 Cimento portland - Determinação do tempo de pega. Rio de Janeiro, 2003.

[25] Associação Brasileira De Normas Técnicas. NBR 7215 Cimento Portland - Determinação da resistência à compressão. Rio de Janeiro, 1996

[26] Associação Brasileira De Normas Técnicas. NBR NM 46 Agregados - Determinação do material fino que passa através da peneira $75 \mu \mathrm{m}$, por lavagem. Rio de Janeiro, 2003; 
[27] Associação Brasileira De Normas Técnicas. NBR NM 248 Agregados - Determinação da composição granulométrica. Rio de Janeiro, 2003.

[28] Associação Brasileira De Normas Técnicas. NBR NM 45 agregados determinação da massa unitária e do volume de vazios. Rio de Janeiro, 2006.

[29] Associação Brasileira De Normas Técnicas. NBR NM 53 Agregado graúdo - Determinação de massa específica, massa específica aparente e absorção de água. Rio de Janeiro, 2003.

[30] Ramos, G. M. Análise Das Propriedades Do Concreto Permeável Com Adição De Agregado Miúdo E Resíduo (Cinza De Madeira). Universidade Federal de Santa Catarina. Centro Tecnológico de Joinville. Trabalho de Conlusão de Curso (graduação). 2018.2 Disponível em: $<$ https://repositorio.ufsc.br/xmlui/bitstream/handle/123456789 /191840/\%28Correcao\%29\%20Concreto\%20Permeavel\%20-

$\%$ 20Gustavo.pdf?sequence $=1 \&$ isAllowed $=\mathrm{y}>$. Acesso em maio de 2019.

[31] Lian, C. Zhuge, Y. Optimum mix design of enhanced permeable concrete - An experimental investigation. Elsevier Journal Constrution and Building Materials, 2010. M. Urban drainage specific climates: urban drainage in humid tropics. Paris: UNESCO. IHPV. Technical Documents in Hydrology. No.40. v.I. cap.4, p $103-124$.

[32] Associação Brasileira De Normas Técnicas. NBR 5738 Concreto - Procedimento para moldagem e cura de corpos de prova. Rio de Janeiro, 2015.

[33] Associação Brasileira De Normas Técnicas. NBR 5739 Concreto - Ensaio de compressão de corpos-de-prova cilíndricos. Rio de Janeiro, 2007. 